\title{
AS FEIRAS-LIVRES DA AGRICULTURA FAMILIAR EM ARAPIRACA, ALAGOAS, BRASIL
}

\author{
Danielle Viturino da Silva ${ }^{1}$ \\ (iD) \\ https://orcid.org/0000-0003-0188-3450
}

Janice Rodrigues Placeres Borges ${ }^{2}$

iD ${ }_{\text {https://orcid.org/0000-0002-4981-9178 }}$

\begin{abstract}
RESUMO
A feira-livre caracteriza-se como importante espaço de comercialização que vem resistindo aos padrões do sistema agroalimentar contemporâneo. Assim, tendo em vista a importância desse canal de comercialização, este trabalho teve como objetivo analisar o potencial de impacto socioeconômico das duas feiras-livres na agricultura familiar, localizadas em Arapiraca, Alagoas. Para isso, a pesquisa foi realizada em três etapas, sendo elas: i) revisão bibliográfica, com ênfase em três temáticas, agricultura familiar, circuito curto e feira-livre, ii) utilização de dados secundários para realização de um resgate histórico do município Arapiraca, Alagoas, e iii) pesquisa de campo, com realização de entrevistas, aplicação de questionário fechado e observações in loco. A partir disso, verificou-se que as duas feiras caracterizadas como universo de estudo desta pesquisa qualificam-se com papel importante dentro do contexto socioeconômico dos agricultores familiares participantes, por possibilitar maior retorno financeiro através da venda direta e exclusão da participação dos atravessadores nas vendas. Além disso, o grupo de produtores orgânicos evidenciou a satisfação em saber que vendem produtos saudáveis, sem uso de agrotóxicos. Por fim, pode-se dizer que a gestão municipal vem sendo um dos principais incentivadores para a continuidade e manutenção das duas feiras, visto que disponibilizam as barracas, transporte para levar os produtos até as feiras e assistência técnica nas propriedades.
\end{abstract}

Palavras-chave: Circuito Curto de Comercialização. Comércio Justo. Mercado Local. Produtos Orgânicos.

\section{FREE FAIRS OF FAMILY AGRICULTURE IN ARAPIRACA, ALAGOAS, BRAZIL}

\begin{abstract}
The open market is classified as an important commercial space, which has been resisting the standards of the modern agri-food system. Thus, in view of the importance of this commercialization channel, this work aimed to analyze the possible socioeconomic potential of the two free fairs for family farming, located in Arapiraca, Alagoas. For this, three stages were carried out, i) bibliographic review, with emphasis on three themes, family farming, short circuit and open market, ii) use of secondary data to carry out a historical rescue of the municipality Arapiraca, Alagoas, iii) research field, with interviews, application of a closed questionnaire and on-site observations. From this, it was found that the two fairs characterized as the study universe of this research, qualify with an important role within the socioeconomic context of the participating family farmers, as it allows greater financial return through direct selling and excluding the participation of middlemen in the sales. In addition, the group of organic producers showed their satisfaction in knowing that they sell healthy products, without using pesticides. Finally, it can be said that the municipal management has been one of the main incentives for the continuity and maintenance of the two fairs, since they provide stalls, transport to take the products to the fairs and technical assistance in the properties.
\end{abstract}

Keywords: Fair Trade. Local Market. Organic Products. Short Food Supply Chains

\footnotetext{
1 Mestre em Agroecologia e Desenvolvimento Rural. PPGADR/Universidade Federal de São Carlos. E-mail: viturino.dani@gmail.com.

${ }^{2}$ Professora do Centro de Ciências Agrárias, Universidade Federal de São Carlos. E-mail: janice@ufscar.br.
} 


\section{RESUMEN}

El mercado abierto se clasifica como un espacio comercial importante, que se ha resistido a los estándares del sistema agroalimentario moderno. Así, en vista de la importancia de este canal de comercialización, este trabajo tuvo como objetivo analizar el posible potencial socioeconómico de las dos ferias gratuitas para la agricultura familiar, ubicadas en Arapiraca, Alagoas. Para ello, se llevaron a cabo tres etapas, i) revisión bibliográfica, con énfasis en tres temas, agricultura familiar, corto circuito y mercado abierto, ii) uso de datos secundarios para llevar a cabo un rescate histórico del municipio Arapiraca, Alagoas, iii) investigación campo, con entrevistas, aplicación de un cuestionario cerrado y observaciones in situ. A partir de esto, se encontró que las dos ferias caracterizadas como el universo de estudio de esta investigación, califican con un papel importante dentro del contexto socioeconómico de los agricultores familiares participantes, ya que permite un mayor retorno financiero a través de la venta directa y excluye la participación de intermediarios en las ventas. Además, el grupo de productores orgánicos mostró su satisfacción al saber que venden productos saludables, sin usar pesticidas. Finalmente, se puede decir que la gestión municipal ha sido uno de los principales incentivos para la continuidad y mantenimiento de las dos ferias, ya que proporcionan puestos de venta, transporte para llevar los productos a las ferias y asistencia técnica en las propiedades.

Palabras-clave: Corto Circuito de Comercialización; Comercio Justo. Mercado Local. Productos Orgánicos.

\section{INTRODUÇÃO}

A agricultura brasileira possui grande importância dentro do sistema agroalimentar, seja pela empregabilidade do homem no campo ou, ainda, pela produção de alimentos para o abastecimento interno. Com base em dados do extinto Ministério do Desenvolvimento Agrário (MDA), de 2009, o setor da agricultura de base familiar vem sendo responsável por $74 \%$ das pessoas ocupadas no campo, e por $70 \%$ dos alimentos agrícolas destinados ao abastecimento interno. Sendo assim, compreendese a importância que a agricultura familiar possui para as famílias rurais, como também para a sociedade em geral, por garantir sua alimentação.

Para Aquino e Schneider (2010), desde 1990 essa categoria ganhou força e vem conquistando seu espaço e legitimidade no cenário brasileiro. No entanto, apesar da importância e dos avanços desse setor, Maluf (2004) aponta que a cadeia agroalimentar estabelece padrões que acabam restringindo a participação dos agricultores familiares no mercado. Scarabelot e Schneider (2012) corroboram essa ideia e apontam que a comercialização dos produtos advindos da agricultura familiar ainda é um grande entrave para esses agricultores.

Sendo assim, em busca de uma lógica que quebre esses padrões estabelecidos, nos últimos anos, pesquisadores intensificaram as discussões sobre circuitos/cadeias curtas de comercialização (CCC). 
De acordo com Darolt, Lamine e Brandemburg (2013) e Darolt et al. (2016), ainda há uma lacuna científica sobre esse tema no Brasil por não haver uma definição oficial para os Circuitos Curtos de Comercialização (CCC). Mas, apesar das limitações a respeito, alguns especialistas tratam o termo como comercialização local, em que os modos de troca e circulação das mercadorias se baseiam no comércio justo e solidário tanto para os produtores como consumidores. Outra característica importante se refere ao número reduzido de atravessadores, configurando-se como venda direta, em que se pode ter até um atravessador.

Dentro dessa perspectiva de CCC, tem-se, como exemplo, as feiras-livres, as cestas a domicílio, vendas na propriedade, vendas à beira de estradas, Comunidade que Apoia a Agricultura (CSA), mercados institucionais (Programa de Aquisição de Alimentos (PAA), Programa Nacional de Alimentação Escolar (PNAE)), lojas especializadas, entre outros.

Essa lógica de mercados alternativos promove a aproximação entre os produtores e consumidores que, por sua vez, revitaliza redes alimentares alternativas por favorecer e fortalecer a reprodução das culturas alimentares regionais.

Nesse aspecto, Godoy e Dos Anjos (2007) afirmam que a feira-livre desempenha papel importante dentro do contexto de consolidação econômica e social da agricultura familiar, sendo, ainda, um espaço público responsável pelas interações culturais dentro do território no qual a feira está localizada.

Tanto as feiras como a venda direta em domicílio geram o benefício de o produtor sair da 'invisibilidade' gerada pela presença dos intermediários em cadeias agroalimentares longas. Além disso, caracterizam-se como espaços educativos que promovem relações de confiança e reciprocidade entre os atores, permitindo também, maior autonomia dos agricultores e agricultoras familiares (Silva, 2017; Darolt, 2016).

Nesse sentido, considerando que a feira-livre desempenha importante papel dentro do cenário socioeconômico, por ser um dos CCC mais antigos, que vem resistindo às exigências e competitividade do sistema agroalimentar moderno, este trabalho tem por objetivo analisar o potencial de impacto socioeconômico das duas feiras-livres de agricultura familiar do município de Arapiraca, Alagoas.

Este trabalho está dividido em três seções: i) breve contextualização histórica e socioeconômica de Arapiraca, Alagoas; ii) do surgimento até os dias atuais da tradicional feira-livre, que foi classificada como um marco importante dentro do desenvolvimento do município; e iii) resultados e discussão, com a caracterização e discussão sobre o potencial das duas feiras escolhidas como objeto de estudo. 


\section{MATERIAL E MÉTODOS}

Para a realização deste estudo de caso, optou-se pelas abordagens quantitativa e qualitativa, pela necessidade de se conhecer a fundo as duas feiras da agricultura familiar realizadas no município de Arapiraca, AL, Brasil.

Os dados quantitativos são importantes na construção do conhecimento por clarificar a realidade encontrada na pesquisa de campo. Já os dados qualitativos, captam a subjetividade encontrada nas falas dos entrevistados, por ter natureza mais aberta e interativa, e, também, por envolver a observação do entrevistador.

Os agricultores e agricultoras familiares participantes da pesquisa têm a agricultura como principal fonte de renda familiar desde a infância. Entretanto, no contexto de experiência como agricultor familiar, os referidos participantes possuem vivência há, pelo menos, quinze anos.

Ao todo, foram entrevistados dez produtores, sendo sete mulheres e três homens, com idades entre trinta e sessenta anos. Dos dez, oito estão inseridos na produção de base orgânica e dois ainda destinam suas atividades para agricultura convencional.

Para a execução desta pesquisa foi necessário efetuar: (1) revisão bibliográfica e documental. (2) pesquisa de campo com realização de entrevista semiestruturada, aplicação de questionário fechado e observações in loco.

1) Procedimentos:

a) Avaliação e aprovação do projeto pelo Comitê de Ética em Pesquisa em meados de março do ano vigente;

b) Revisão de literatura, alicerçada em três temáticas: agricultura familiar, circuito curto e feira-livre;

c) Realização de pesquisas documentais, tendo como referência bibliográfica os relatórios, as publicações técnicas, científicas e analíticas produzidas por meio da Biblioteca Pública Municipal Pedro de França Reis, Companhia de Desenvolvimento dos Vales do São Francisco e do Parnaíba (CODEVASF), Atlas do desenvolvimento humano no Brasil e do Banco do Nordeste;

d) Pesquisa de campo entre março e abril de 2019, com realização de i) entrevistas a fim de conhecer a realidade local, e ii) aplicação de questionário dividido em três eixos: I - perfil socioeconômico, II - funcionamento do circuito curto de comercialização (feiras), III - avaliação da feira.

e) Por último, separação dos dados a serem analisados; tabulação; análise e interpretação. 
BREVE CONTEXTUALIZAÇÃO HISTÓRICA E SOCIOECONÔMICA DE ARAPIRACA, ALAGOAS

O fundador de Arapiraca, Manoel André Correia dos Santos, mudou-se de Cacimbinhas-AL em busca de terras com clima mais favorável para seus trabalhos agrícolas, juntamente com sua esposa Maria da Silva Valente. No decorrer de 1848, embaixo de uma frondosa árvore de Arapiraca (Figura 1) resolveram descansar e ali construir sua casa. Por essa razão, Manoel André deu ao lugar o nome de Arapiraca (Macedo, 1992).

Figura 1 - Árvore de Arapiraca

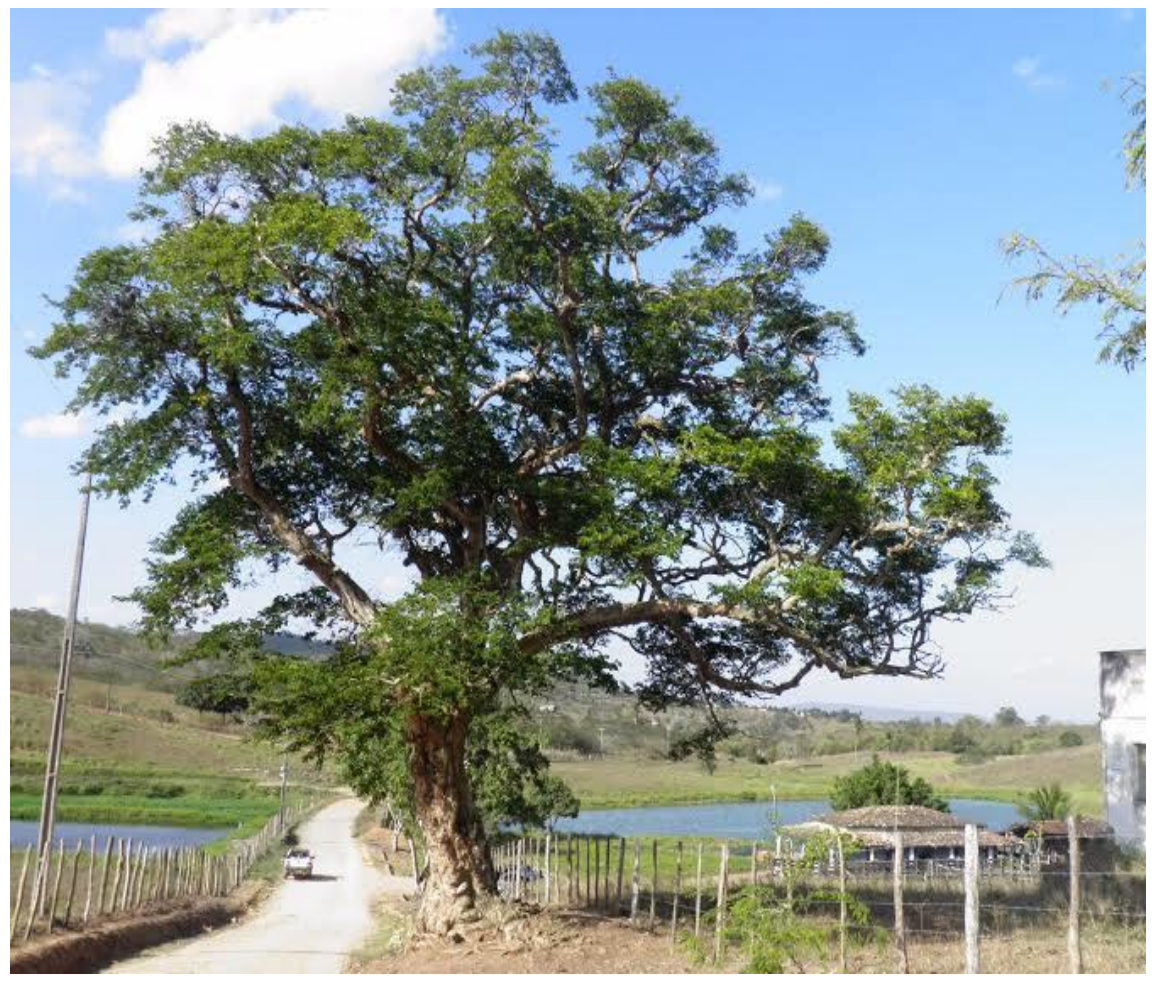

Fonte: Arquivo da Prefeitura de Arapiraca, 2019

Nos anos seguintes, o local começou a ser povoado, originando-se os demais bairros. Inicialmente, as atividades econômicas giraram em torno, predominantemente, do fumo (Figura 2). À vista disso, Arapiraca ficou conhecida como a cidade do fumo pelo Brasil. Conforme Oliveira (2007, p. 22) na década de 1960, o setor fumageiro alcança grande crescimento econômico e “[...] a microrregião de Arapiraca ganha então referência de ser o maior parque fumageiro da América Latina em área contínua, devido à propagação da folha de fumo em praticamente todos os municípios da mesorregião do Agreste Alagoano". Vale destacar que, paralelamente ao plantio do fumo, a agricultura de subsistência era uma prática recorrente, como a pecuária, o algodão, feijão de corda, milho e mandioca. 
Figura 2 - Fábrica de fumo

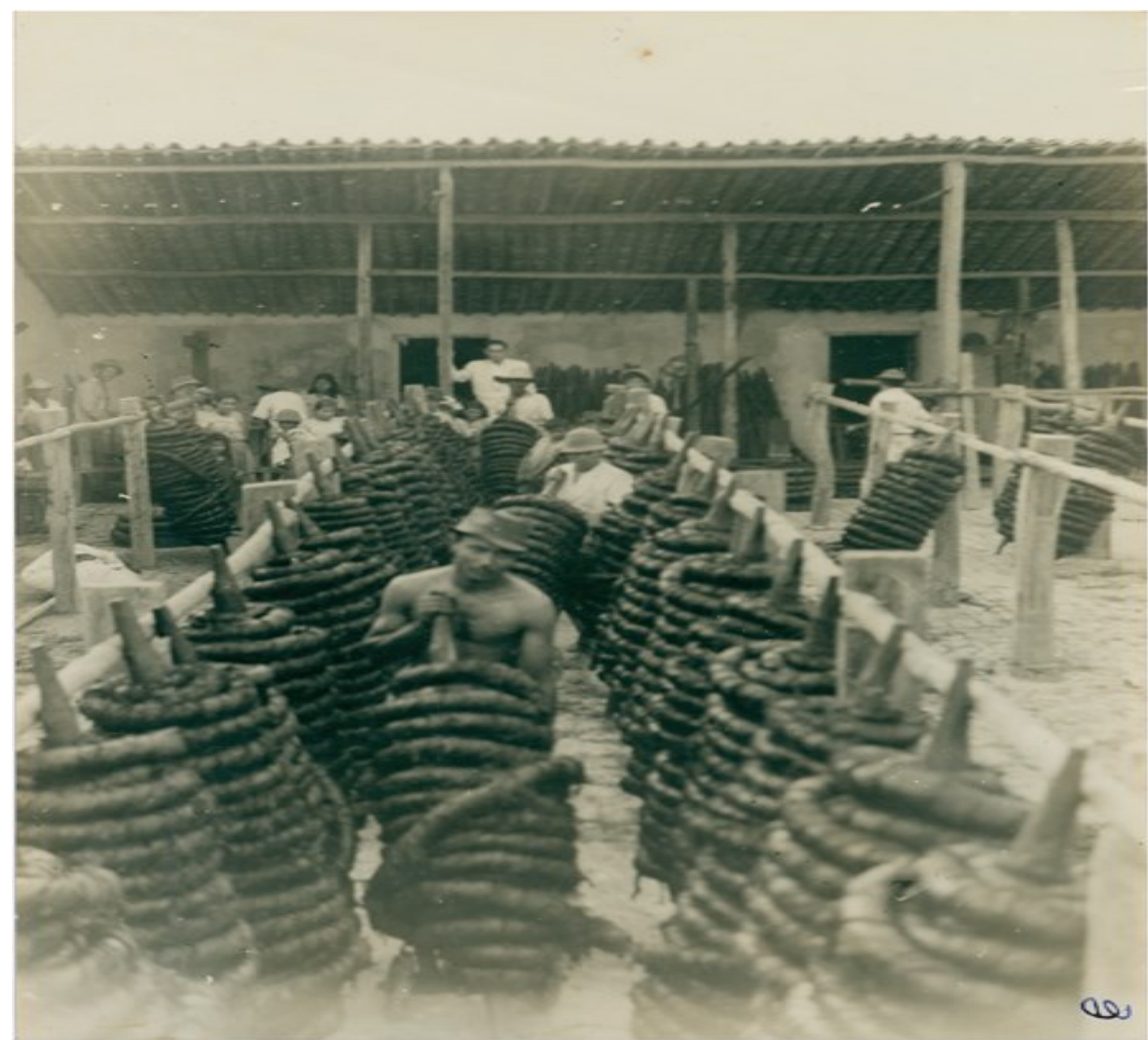

Fonte: Arquivo da Prefeitura de Arapiraca, 2019.

Em virtude do grande sucesso que a cultura do fumo apresentava, muitos agricultores da região e empresas estrangeiras adotaram a mesma, e, entre 1975 e 1980, aparece a crise de superprodução. De acordo com Oliveira (2007, p. 23), os fatores que propulsionaram a crise do setor fumageiro foram "a baixa qualidade do produto, o seu excesso de oferta, o reduzido nível de informação dos produtores, o forte grau de distorção no processo de comercialização e a tendência estrutural da redução da demanda por fumo assumem grande importância [...]”.

A partir da década de 90, devido ao aumento na oferta e ao grande número de investidores, o setor entra em estagnação. Logo, os agricultores e o poder público buscaram novas possibilidades que viabilizassem um bom desempenho econômico para região. Em 2003, o município é impulsionado a um novo ciclo, e a agricultura começa a ganhar maior dimensão em Arapiraca. Esse novo ciclo é iniciado pela implementação do projeto Amanhã, criado com o objetivo de capacitar mão de obra especializada em horticultura para atender ao projeto Cinturão Verde (Figura 3) do município, que disponibilizou água, através da perfuração de poços artesianos, para a produção de hortícolas (tomate, alface, couve, cebolinha, coentro, pimentão, entre outras). Ambos foram financiados pelo Ministério da Integração Nacional e executados pela CODEVASF, em parceria com a Prefeitura Municipal de Arapiraca (CODEVASF, 2006). 
Figura 3 - Estufa de mudas de hortaliças, da comunidade Batingas

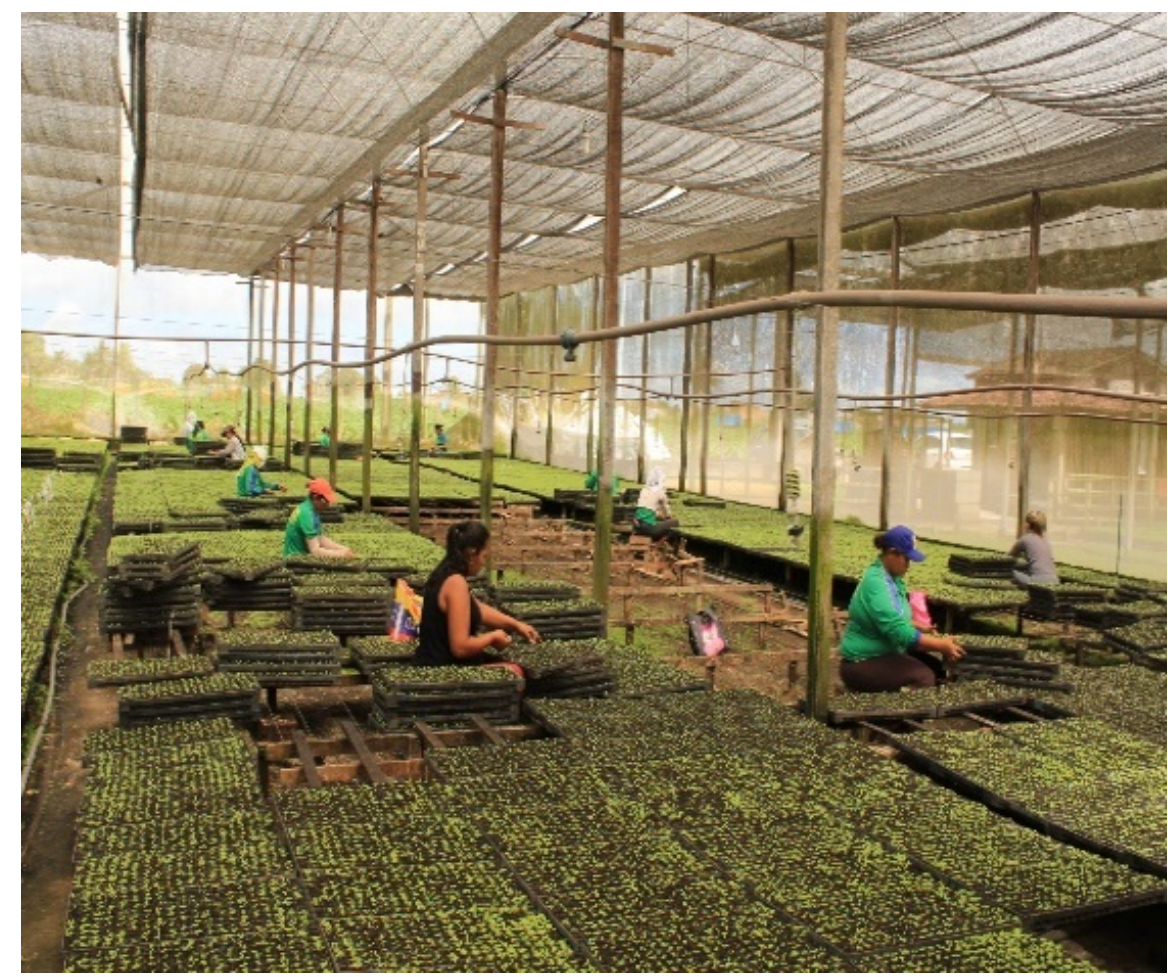

Fonte: Arquivo da Prefeitura de Arapiraca, 2019.

Ainda de acordo com a Codevasf (2006), a implantação do projeto Cinturão Verde foi afortunada. A partir dos dados disponibilizados pela Secretaria Municipal de Agricultura, observouse que a produção de verduras passou de 3,5 mil para 6,4 mil toneladas de produção por ano. A produção, além de atingir a autossuficiência, ainda atuou na exportação de verduras para outras cidades de Alagoas e outros estados.

O município de Arapiraca (Figura 4) compõe a Mesorregião do Agreste Alagoano, e teve sua emancipação política em 30 de outubro de 1924. Ocupa uma área de 352,81 km², com cerca de 214.006 habitantes, sendo que $84,80 \%$ corresponde à população urbana e $15,20 \%$ à rural. Seu Índice de Desenvolvimento Humano (IDH), apurado no ano de 2010, é de 0,649, sendo considerado uma escala de desenvolvimento médio (BRASIL, 2019). 
Figura 4- Mapa do estado de Alagoas

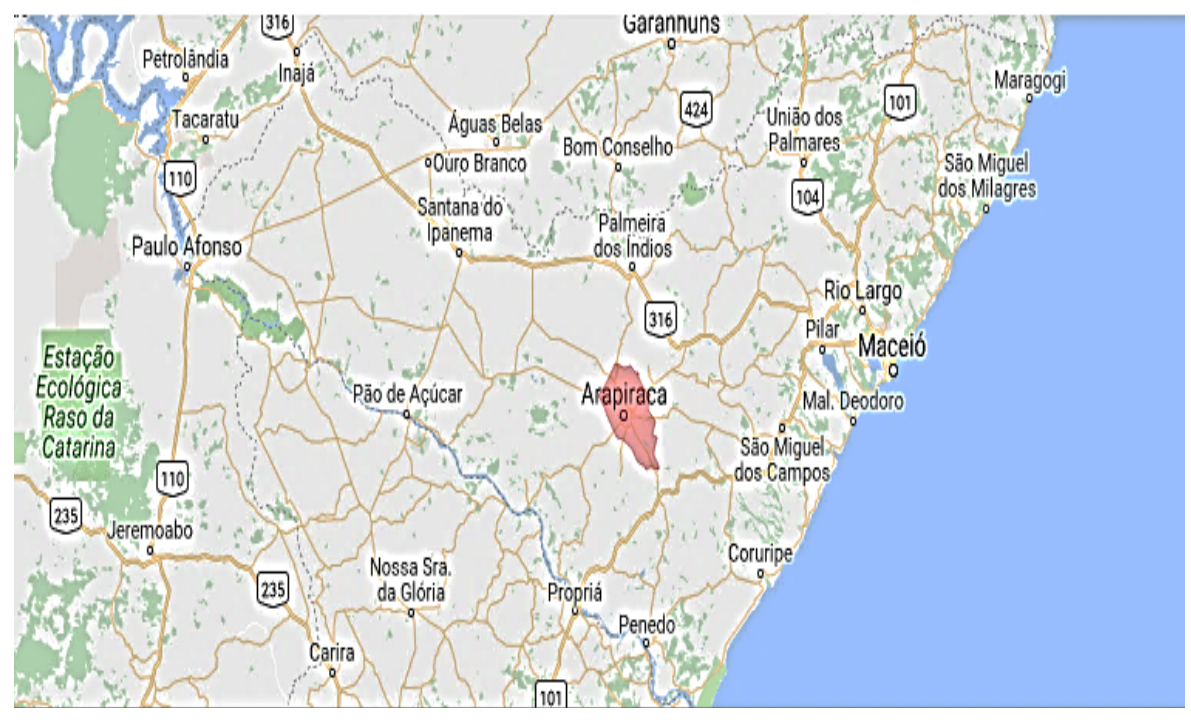

Fonte: BRASIL, 2019.

Arapiraca, apesar de ser afastada do mar e de lagoas, sem vegetações de mangues e mata atlântica, não deixou de ser caracterizada como um importante polo de turismo interno. A região é a segunda cidade mais populosa e o segundo centro econômico do estado, sendo que, em 2014, sua participação setorial no PIB por unidade geográfica estava voltada, principalmente, para o setor de serviços (60,6\%), Administração Pública (21,5\%) indústria $(9,9 \%)$ e agropecuária $(8,0 \%)$ (BANCO DO NORDESTE, 2017).

O município, além de constituir-se um importante entreposto comercial, por oferecer uma diversa variedade de bens e serviços para a população regional, ainda, juntamente com as microrregiões de Palmeira dos Índios, Batalha e Santana do Ipanema, entre outras, formam a bacia leiteira do estado de Alagoas.

Para Nardi (2010), outro fator preponderante dentro da história de povoamento do município de Arapiraca foi o surgimento da feira-livre: "O fumo e a feira-livre são os dois pilares históricos da economia arapiraquense e estão na origem das vocações agrícolas e comerciais profundamente enraizadas na cultura do povo [...]" (NARDI, 2010, p. 41). Assim, o próximo tópico destina-se a descrever como foi o surgimento das feiras-livres e sua importância para o desenvolvimento em Arapiraca.

DO SURGIMENTO AOS DIAS ATUAIS DA TRADICIONAL FEIRA-LIVRE EM ARAPIRACA, ALAGOAS

A presença das feiras-livres no Nordeste é uma característica marcante da região. Seu surgimento na região ocorre mediante o intenso comércio destinado às atividades pecuárias em meados do século XVIII e XIX. Isso porque a pecuária consolidou a população nas áreas do Agreste 
e Sertão Nordestino, possibilitando a criação das relações comerciais, inicialmente, voltada para o gado. Em seguida, sucede-se a evolução dessas relações para as atuais feiras livres (DANTAS, 2008).

Ainda de acordo com autor, "a feira livre possui grande importância dentro da formação socioeconômica nordestina, por se caracterizar como uma das principais formas de comercialização agrícola" (DANTAS, 2008. P. 92).

Pensando em como as feiras se originaram, Nardi (2010) propõe que elas surgiram com a necessidade de os produtores venderem seus excedentes e/ou trocar suas mercadorias com outras que não produziam.

Em Arapiraca, a feira livre (figura 5) originou-se em 1884, época em que a cidade iniciava sua povoação. A mesma ganhou maior dimensão com a chegada da cultura fumageira, que trouxe consigo uma expressiva população flutuante (Arapiraca, 1993).

Figura 5- Tradicional feira livre localizada em rua do comércio, entre a entrada para o alto do cruzeiro e a igreja de Arapiraca-AL

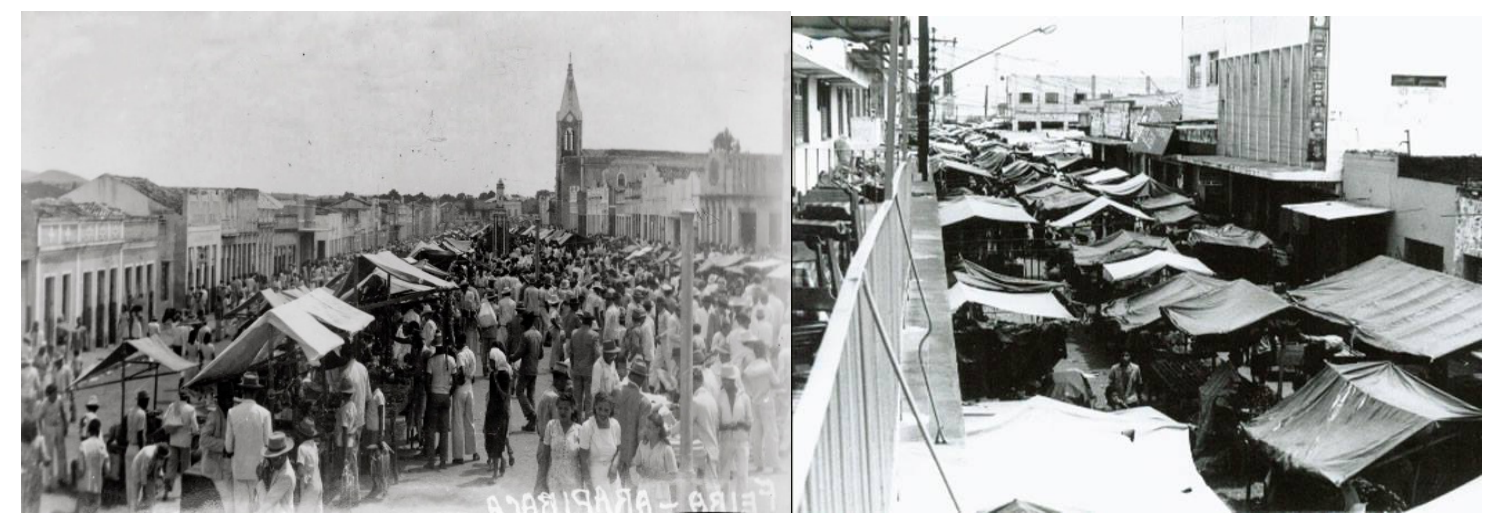

Fonte: Arquivo da Prefeitura de Arapiraca, 2019.

Para Nardi (2010), a feira-livre surge como uma exigência e não da vontade de uma única pessoa. Nesse sentido, sugere que "[...] Deve ter havido um motivo particular para o estabelecimento da feira em Arapiraca. O fumo foi provavelmente o principal responsável pelo aparecimento da feira." (Nardi, 2010, p. 42).

Pode-se dizer que a tradicional feira de Arapiraca se caracteriza como importante fator que motivou os seus habitantes a buscarem a emancipação, ocorrida em 1924. O sucesso da feira era inegável. Com a evolução do município como polo regional, ela assumiu grande proporção, constituindo-se em um verdadeiro complexo e, ocupando cerca de vinte ruas com produtos de base quase toda regional (Guedes, 1992).

A feira de Arapiraca, nas décadas de 40 e 50, foi tida como uma das maiores do Brasil, devido a sua extensão por várias ruas do centro da cidade (Arapiraca, 2004). 
Com base nos historiadores Macedo (1992) e Guedes (1992), a feira-livre foi um instrumento determinante na evolução de Arapiraca. Os fatores propulsores que facilitaram tal empreendimento foram: "a localização privilegiada, a força do trabalho do povo e a vocação para o crescimento. [...]" (Nardi, 2010, p. 41).

Desde 1884, a feira-livre de Arapiraca representa um espaço que vai além de relações comerciais, já que serviu de inspiração para nomes da música (emboladores, repentistas, sanfoneiros), dança, teatro, literatura de cordel, poesia. Dentro do campo da música, tem-se, como exemplo, Hermeto Pascoal, natural de Lagoa da Canoa (AL), que buscou, por meio dos sons da feira, inspiração para sua formação musical, hoje reconhecida mundialmente.

Balbino (2017) relata que, dentro do contexto da feira, a arte é algo presente, e, segundo o próprio Hermeto Pascoal, se hoje ele faz "música universal é porque na feira de Arapiraca já se fazia música universal”.

Esse cenário corrobora a ideia de que a feira se caracteriza como um canal de comercialização, responsável pelo elo entre as relações econômicas, sociais e culturais.

Nesse contexto, percebe-se que as feiras “[...] contribuem para o fortalecimento de um espaço de sociabilidade, extremamente dinâmico e diversificado sob o plano social, econômico e cultural, onde os indivíduos encontram maneiras de se ajudar, trocar informações e até fazer planos de aquisição conjunta." (Sposito; Abreu, 2017, p. 299).

Ainda, numa perspectiva sobre a origem da feira em Arapiraca, alguns autores levantam a hipótese de que a feira livre surgiu como medida de combater a fome pela qual a população passava. Em 1924, o prefeito da capital de Alagoas inspirou-se nessa forma de comércio desenvolvida em Arapiraca e anos depois criou três feiras-livres na sua cidade. "[...] As feiras eram temporais e regulamentadas, destinadas antes à venda dos gêneros alimentícios de primeira necessidade a preço tabelado [...]". Essa medida foi tomada como forma de permitir às famílias mais carentes o acesso à alimentação (Nardi, 2010, p. 47).

A psicóloga Leny Sato, em uma discussão sobre algumas feições dos processos cotidianos que organizam o trabalho na feira-livre, aponta que “[...] A feira-livre deve ser compreendida, então, como um contínuo organizar, baseado em acordos e negociações, em cooperação e competição e na execução de regras tácitas. Isso garante a agilidade, a extrema adaptabilidade e a criatividade de formas de se fazer a feira-livre" (Sato, 2007, p. 99).

Inicialmente, a feira em Arapiraca, como já mencionado, atingiu um expressivo número de ruas localizadas, principalmente, no centro da cidade. Toda essa movimentação causou grande sucesso e atraiu grande concentração de pessoas da região que se deslocavam até a feira para realizarem as compras semanais. Por outro lado, o sucesso gerado a partir das feiras causou insatisfações, na época, na maioria dos comerciantes mais capitalizados da região. Diante disso, 
Guedes (1992) afirma que, com o passar do tempo, devido à insatisfação dos comerciantes e ao desejo dos mesmos em acabar com as feiras, o resultado dessa movimentação seria a extinção da feira e a criação de um moderno e amplo Mercado Central. Esse seria o progresso na evolução dos tempos. Com isso, a cidade perderia a paisagem humana encontrada nas feiras, que é algo impressionante, pois os tipos humanos formam um valioso conteúdo, além de fornecer subsídios importantes para pesquisadores, sociólogos, fotógrafos e cinegrafistas que frequentam com frequência a feira semanal (ARAPIRACA, 1993).

Entre 2002 e 2003, após várias especulações por parte dos comerciantes e da prefeitura municipal, também buscando melhorar a infraestrutura da tradicional feira, realiza-se a mudança para o bairro Baixão, ficando um pouco afastada do centro da cidade. Fato este que ocasionou insatisfação por parte dos feirantes e consumidores.

Após sete meses de mudança, os feirantes, o comércio e população demostraram sua insatisfação. Os feirantes alegaram uma queda de $90 \%$ das vendas. Todo esse desagrado foi em decorrência da distância. Na época, o historiador Zezito Guedes afirmou que a tradicional feira estaria extinta (Feira, 2003).

Medeiros (2003) corrobora este fato e aponta que a feira já havia sido considerada a maior do interior de Alagoas, o que ajudou no processo de colonizar as terras de Manoel André, ficando famosa no mundo inteiro por sua tradição.

Atualmente, no lugar onde as barradas eram expostas, há um bonito calçadão, com diversas lojas de roupas, eletrodomésticos, tecidos, utensílios em geral. A tradicional feira continua no bairro Baixão, comercializando produtos in natura como frutas, legumes e verduras. Há também produtos processados como pães, bolachas, massas, sucos, etc.; comidas típicas, como bode assado, sarapatel de boi e porco, buchada, entre outros. Sendo possível encontrar também roupas, calçados, brinquedos, móveis e utensílios em geral.

Após, aproximadamente, 16 anos da mudança, a feira continua ocorrendo toda segunda-feira, seguindo a tradição, e as barracas são distribuídas em nove ruas. Ressalta-se que o número de bancas expostas diminuiu um pouco, comparando-se com os anos anteriores à mudança. Apesar disso, percebe-se que a tradição continua firme e forte. Na feira, há uma gama variada de produtos de qualidade a preços acessíveis, com exceção dos períodos em que se tem uma variação nos preços devido à época de cada cultura e/ou questões climáticas.

Paralelamente, na cidade também ocorrem feiras nos outros dias da semana, cada uma em um bairro estratégico. Ao todo, são onze feiras 'convencionais', distribuídas em vinte e nove ruas da cidade. Em 2010, criou-se mais uma feira, sendo está destinada apenas aos agricultores familiares da região. Em 2017, houve a extensão desta para o hall do shopping da cidade. Essas duas feiras caracterizam-se como o universo de estudo desta pesquisa. 


\section{RESULTADOS E DISCUSSÃO}

Caracterização das duas feiras da agricultura familiar

Este trabalho possui como universo de pesquisa as duas feiras de Agricultura Familiar denominadas como 'Feira Popular da Agricultura Familiar'. Como se tratam de duas feiras, para melhor compreensão dos leitores, a mais antiga, que ocorre no Parque Municipal Ceci Cunha, receberá a identificação de Feira 01, e a mais recente, que funciona no Garden Shopping, será Feira 02.

A Feira 01 (Figura 6), criada em 2010, acontece no Parque Municipal Ceci Cunha, com horário de funcionamento aos sábados, das $8 \mathrm{~h}$ às $12 \mathrm{~h}$. Possui, aproximadamente, dez agricultores(as) familiares comercializando frutas, grãos, hortaliças, tubérculos (raízes), mel, etc.

Figura 6 - Feira Popular da Agricultura Familiar, localizada no Parque Municipal Ceci

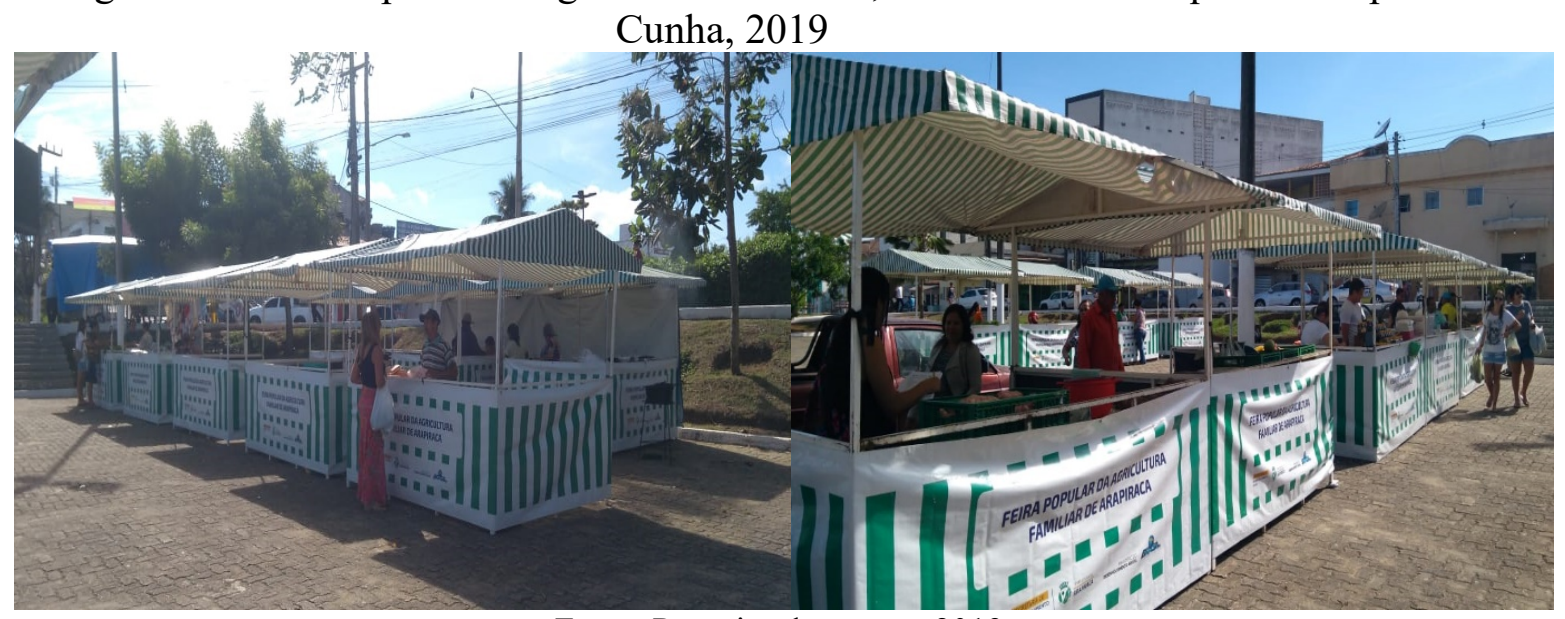

Fonte: Pesquisa de campo, 2019.

A Feira 02 (figura 7) foi inaugurada em março de 2017 e está localizada no Garden Shopping. Ocorre entre $8 \mathrm{~h}$ e $14 \mathrm{~h}$, às quartas-feiras. Possui, aproximadamente, oito agricultores(as) comercializando hortaliças, frutas, queijos, mel, etc.

Figura 7 - Feira Popular da Agricultura Familiar, localizada no Garden Shopping, 2019

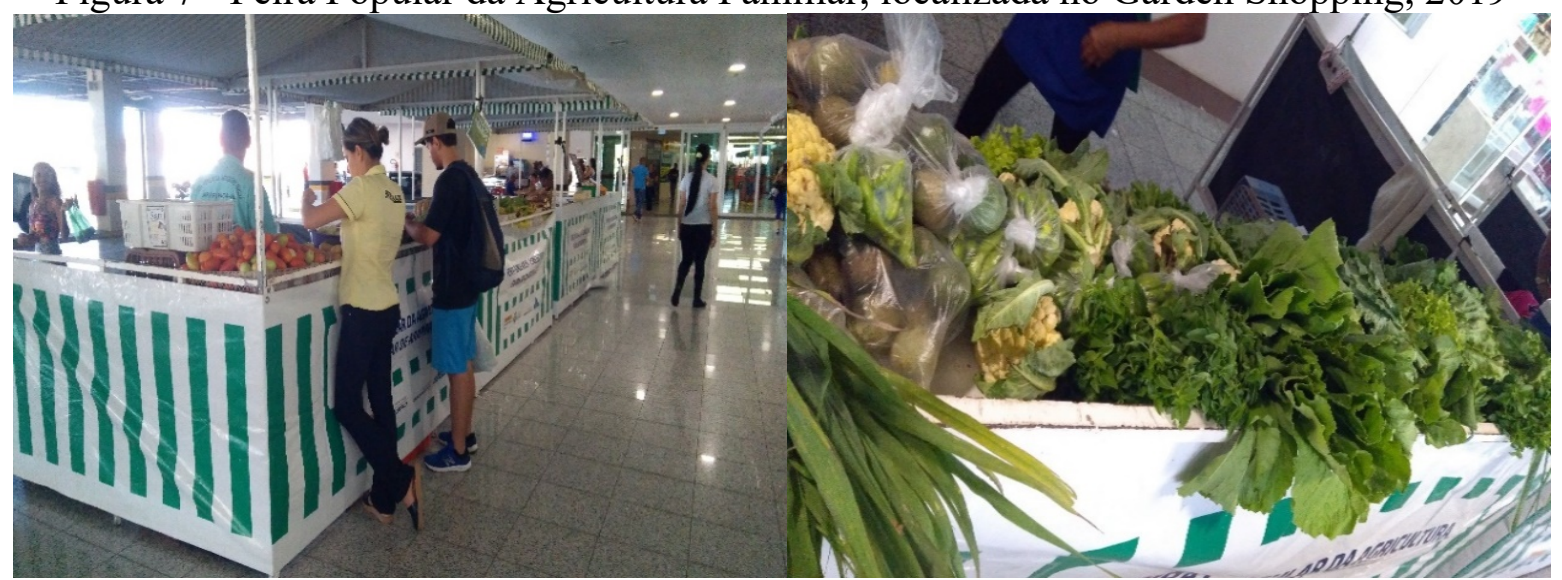

Fonte: Pesquisa de campo, 2019. 
No quesito infraestrutura, observou-se uma padronização nas barracas, e boa conservação, como pode ser observado nas figuras acima.

A criação das duas feiras foi iniciativa da gestão municipal, como forma de proporcionar mudança na realidade socioeconômica dos agricultores. Além disso, a prefeitura vem disponibilizando as barracas, o transporte para ida e volta da feira, assim como assistência técnica nas propriedades.

Nos dois locais, os consumidores podem encontrar produtos orgânicos, que são comercializados por oito dos onze feirantes. Os três feirantes restantes comercializam produtos 'convencionais'. Nos dois locais, há identificação dos produtos orgânicos e convencionais.

Os feirantes que comercializam produtos orgânicos são cadastrados na Organização de Controle Social (OCS), e, através desse cadastro, é fornecido um documento de conformidade de produção orgânica participativa. Nesse documento, consta os dados do produtor, da propriedade e o número de cadastro.

É importante ressaltar que a Feira 02 que vem ocorrendo no hall do Garden Shopping, é uma extensão da Feira 01, que ocorre no Parque Municipal Ceci Cunha. Sendo assim, os feirantes são os mesmos nas duas feiras. Entretanto, dois feirantes da Feira 01 não participam da Feira 02, ou seja, dos dez feirantes, apenas oito comercializam seus produtos no hall do Garden Shopping.

No que concerne ao público alvo de cada feira, verificou-se que os públicos são distintos. $\mathrm{Na}$ Feira 01, observou-se a predominância de adultos e idosos. Já na Feira 02, a partir das observações in loco, constatou-se que há uma maior demanda dos produtos pelos jovens e adultos que frequentam a academia que funciona no Shopping.

Discutindo o potencial socioeconômico das feiras da agricultura familiar em Arapiraca, Alagoas

A feira-livre faz parte da história da cidade de Arapiraca, presente desde o início de sua povoação até os dias atuais, representando um espaço que permeia relações econômicas, sociais e culturais. Tal fato foi evidenciado durante a pesquisa de campo, uma vez que, durante as visitas, presenciou-se a realização de um evento cultural na Feira 01, em comemoração ao dia do apicultor. Além disso, com base nos relatos, o contato direto com o consumidor possibilita a construção de relações pautadas na confiança e respeito.

Tendo isso em vista, observa-se que as duas feiras da agricultura familiar, apresentam-se como importante mecanismo de comercialização na vida dos agricultores. Tal situação é refletida por possibilitar o contato direto com o consumidor, obtendo maior retorno financeiro. Este cenário 
dificilmente é encontrado em circuitos longos de comercialização (redes atacadistas, supermercados) ou quando há a presença de atravessadores.

Os circuitos curtos potencializam uma conexão direta entre os agricultores e consumidores, possibilitando a formação da sua própria rede e ampliando o capital social dos agricultores. Em outros termos, o CCC permite maior interação na construção de relações mútuas de confiança e reciprocidade entre os agentes envolvidos (SOUZA-SEIDL; BILLAUD, 2015; SCARABELOT; SCHNEIDER, 2012).

Gráfico 1 - Canais de comercialização acessados antes e depois da Feira Popular da Agricultura Familiar

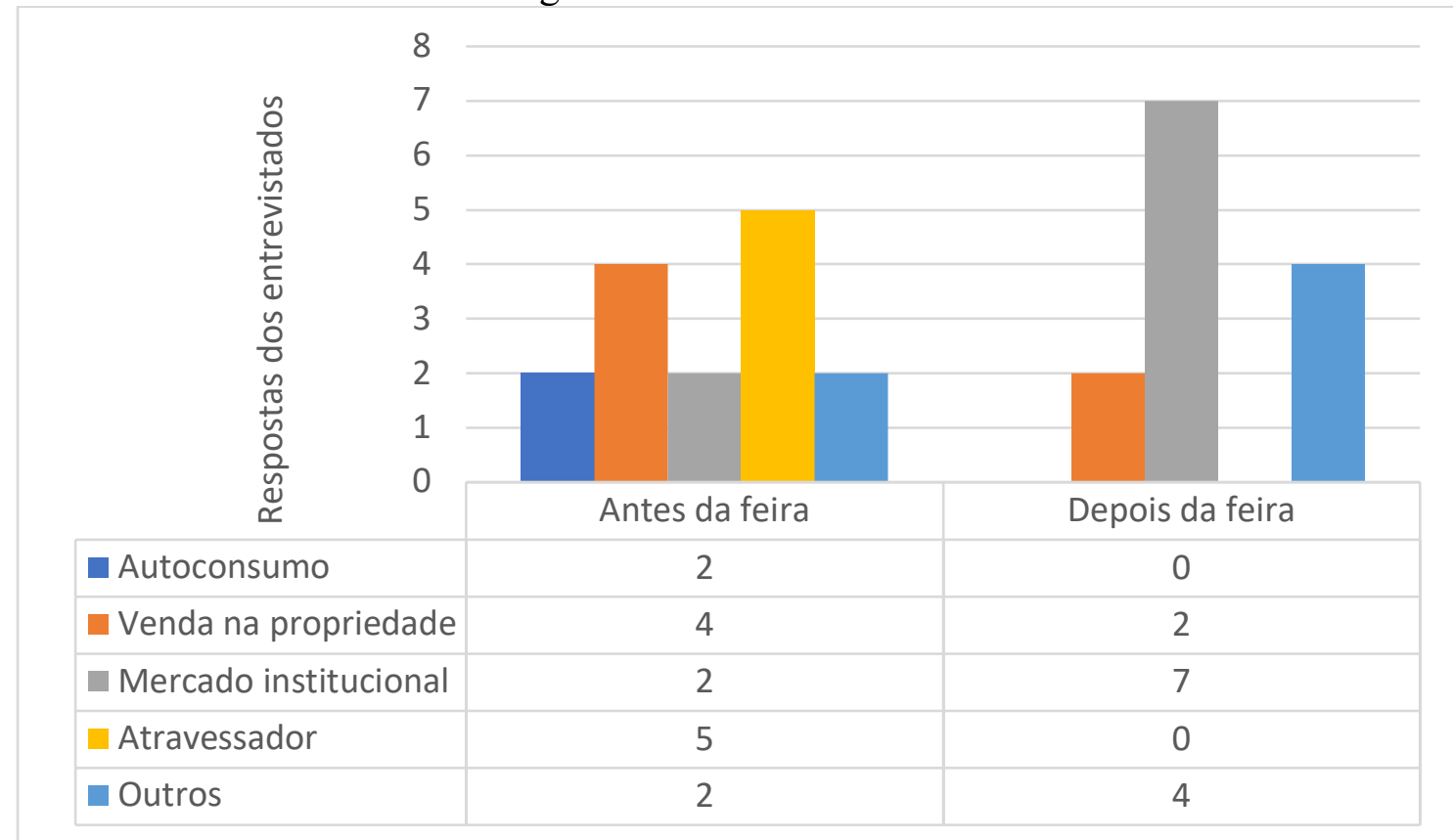

Fonte: Pesquisa de campo, 2019.

O gráfico 1 ilustra o cenário antes e depois do surgimento da 'Feira Popular da Agricultura Familiar'. Verifica-se que, antes da existência das feiras, cinco dos agricultores realizavam suas vendas por meio dos atravessadores. Após a feira, o atravessador sai de cena, com isso, os agricultores relataram aumento na renda, pois antes o retorno era baixíssimo. Por exemplo, o coentro, que era vendido a $\mathrm{R} \$ 0,05$ para os atravessadores, agora, com a venda direta ao consumidor, o preço varia de $\mathrm{R} \$ 1$ a R\$1,50.

Outro ponto importante observado no gráfico refere-se ao autoconsumo. Antes da feira, dois dos onze agricultores destinavam sua produção apenas para subsistência da sua família. Agora esses agricultores aumentaram e diversificaram sua produção, conseguindo um retorno financeiro a partir de suas atividades no campo. Cabe ressaltar que o autoconsumo continua existindo por parte dos dez agricultores(as) familiares entrevistados. 
Durante a pesquisa, foi questionado sobre o que motivou a participação dos agricultores e agricultoras familiares nessas feiras. Após análise dos dados, verificou-se que eles já buscavam espaço/local para escoarem seus produtos e terem retorno financeiro justo. Tal busca se concretizou com o surgimento da primeira feira destinada aos agricultores familiares em 2010. Desde então, os agricultores e agricultoras acessam esse canal curto de comercialização para escoarem seus produtos diretamente ao consumidor, tendo, consequentemente, o retorno financeiro aumentado, visto que se pratica o comércio justo sem a presença do atravessador.

Os agricultores dividiram opiniões sobre a avaliação da feira. Três avaliaram como ótima, quatro como boa e três como regular. No geral, os dez feirantes relataram que, através da feira, eles conseguiram maior estabilidade financeira, pois as vendas aos atravessadores traziam pouco retorno financeiro.

O cenário encontrado nas duas feiras corroboram a abordagem proposta por Scarabelot e Schneider (2012), quando afirmam que o processo de fortalecimento dos agricultores familiares está conectado com o surgimento das cadeias agroalimentares curtas, pois uma de suas principais características “[...] refere-se a sua capacidade de ressocializar ou "reespacializar" o alimento, que possibilitado movimentos positivos para os consumidores tanto quanto para os agricultores familiares. [...]" (SCARABELOT; SCHNEIDER, 2012, p. 125)

Ao longo das entrevistas, os dez entrevistados reclamaram que há pouca divulgação/publicidade sobre a existência das feiras, apesar da primeira já existir há nove anos. Para eles, a prefeitura precisa divulgar mais os dias de funcionamento, já que nos últimos meses houve uma redução no número de consumidores.

Dentro do campo da divulgação requisitada pelos agricultores, compreende-se que tal exigência caracteriza-se como uma função importante no processo de vendas, uma vez que uma boa divulgação de determinado produto ou serviço pode melhorar em grande proporção as vendas. Conforme Araújo e Marjotta-Maistro (2017), as estratégias de marketing dentro dos mercados de proximidades, como feiras ecológicas, devem possibilitar conexões entre a produção e o consumo, promovendo maior visibilidade desses canais e, consequentemente, atraindo novos consumidores.

Ainda, verificou-se a satisfação em produzir e vender produtos orgânicos. Através disso, os agricultores e agricultoras alegam conseguir contribuir com a segurança alimentar dos consumidores, como também da sua família. Nessa abordagem, Magnanti (2008) discute que a agricultura familiar tem um enfoque comercial que privilegia a segurança alimentar de produtores e consumidores, essa lógica difere da que rege o sistema convencional. 


\section{CONSIDERAÇÕES FINAIS}

Ao longo do trabalho, buscou-se analisar como as duas feiras caracterizadas como circuito curto de comercialização proporcionaram mudança socioeconômica na vida dos agricultores e agriculturas em questão. De fato, o contato direto com o consumidor promoveu melhoria financeira, visto que houve aumento na renda familiar após adotarem o CC como instrumento de comercialização. $\mathrm{O}$ aumento na renda ocorreu não só pela prática do comércio justo, encontrado nas feiras, como também pela exclusão de intermediários nas vendas. Como se sabe, em circuitos longos há a presença de mais de um atravessador, que acaba interferindo negativamente no valor que produtores recebem pelos seus produtos.

Além disso, verificou-se que os produtores orgânicos dispõem de alimentos agrícolas variados para venda. Tal iniciativa é uma forma de fugir dos padrões estabelecidos pelo sistema agroalimentar vigente, ao mesmo tempo que incentiva a mudança nos hábitos alimentares dos consumidores e aumenta sua segurança alimentar.

No âmbito da gestão pública, percebeu-se o papel ativo no que se refere à infraestrutura da feira e ao apoio técnico nas propriedades, além, das políticas de abastecimento e segurança alimentar, visto que sete dos produtores acessam o Programa de Aquisição Alimentar (PAA).

No mais, percebeu-se que o processo de revitalização das feiras direcionou para criação de sinergias e coesão social entre os atores envolvidos (agricultores, poder público e sociedade civil), pelo fato de emergir novas facetas do desenvolvimento rural, como a construção de mercado local, apoio à produção orgânica e acesso a alimentos saudáveis no valor justo. Essas ações, por sua vez, fortalecem a agricultura familiar, contribuindo para a sustentabilidade e incentivando a economia local.

\section{AGRADECIMENTOS}

Aos agricultores familiares participantes da pesquisa, que se dispuseram a participar da entrevista, colaborando para a realização da mesma. Ao apoio da Coordenação de Aperfeiçoamento de Pessoal de Nível Superior - Brasil (CAPES) - Código de financiamento 001.

\section{REFERÊNCIAS}

AQUINO, J.; SCHNEIDER, S. (Des)caminhos da política de crédito do PRONAF na luta contra pobreza e a desigualdade social no Brasil rural. In: I Conferência Nacional de Políticas Públicas contra a Pobreza e a Desigualdade. UFRN, v. 1. p. 1-21. Natal. Anais..., 2010. 
ARAPIRACA. PREFEITURA MUNICIPAL: Biblioteca Pública Prof. Pedro de França Reis, Seção Recortes: Alagoas em tempo, 2004.

ARAPIRACA. PREFEITURA MUNICIPAL: Biblioteca Pública Prof. Pedro de França Reis, Seção Recortes: Feira Livre de Arapiraca, 1993.

ARAÚJO, H. M.; MARJOTTA-MAISTRO, M. C. Contribuições das estratégias de marketing e do comportamento do consumidor para a construção do sistema alimentar de base ecológica. Espacios, Vol. 38, n. 29, Pág. 21, 2017.

BALBINO, E. Feira livre fez história e torna Arapiraca referência regional. Prefeitura de Arapiraca, 2017. Disponível em: $<$ http://web.arapiraca.al.gov.br/2017/10/feira-livre-fez-historia-e-tornaarapiraca-referencia-regional/>. Acesso em 10 de jul. de 2019.

BANCO DO NORDESTE. Informações Socioeconômicas Municipais, Município: Arapiraca, Alagoas. Relatório, $2017 . \quad$ Disponível em: $<$ https://www.bnb.gov.br/documents/80223/1309601/Relat\%C3\%B3rio+Arapiraca.pdf/eb35aa2c3f2c-effc-3134-e8ee3ad1b929>. Acesso em 17 de jun. de 2019.

BRASIL, Atlas. Atlas do desenvolvimento humano no Brasil, 2019. Disponível em :< http://www.atlasbrasil.org.br/2013/pt/perfil_m/arapiraca_al >. Acesso em 11 de jun. de 2019.

BRASIL. Ministério do Desenvolvimento Agrário - MDA. Agricultura familiar no Brasil e o Censo Agropecuário 2006. Brasília: $2009 . \quad$ MDA, Disponível em: $<$ https://wp.ufpel.edu.br/consagro/files/2010/09/AF-Censo-2006-MDA.pdf\&gt;.>. Acesso em: 14 jun. 2019.

CODEVASF-Companhia de Desenvolvimento dos Vales do São Francisco e do Parnaíba. Projeto Amanhã em Arapiraca (AL), 2006. Disponível em:< https://www.codevasf.gov.br/noticias/2005/20050707_02>. Acesso em 15 de jun. 2019.

DANTAS, G. P. G. Feiras no Nordeste. Mercator-Revista de Geografia da UFC, v. 7, n. 13, p. 87$101,2008$.

DAROLT, M. R. et al. Redes alimentares alternativas e novas relações produção-consumo na França e no Brasil. Ambiente \& Sociedade, v. 19, n. 2, 2016.

DAROLT, M. R.; LAMINE, C.; BRANDENBURG, A. A diversidade dos circuitos curtos de alimentos ecológicos: ensinamentos do caso brasileiro e francês. Revista agriculturas: Experiências em Agroecologia, v. 10, n. 2, p. 8-13, 2013.

FEIRA livre de Arapiraca ameaçada de extinção. Arapiraca: Alagoas em Tempo, Biblioteca Pública Prof. Pedro de França Reis, 2003.

GODOY, W. I.; DOS ANJOS, F. S. A importância das feiras livres ecológicas: um espaço de trocas e saberes da economia local. Revista Brasileira de Agroecologia, v. 2, n. 1, 2007.

GUEDES, Z. Feira de Arapiraca. In: IV Encontro Estadual Vídeo Escola, Arapiraca, 1992.

MACEDO; V. O. Raízes e frutos de Arapiraca. Biblioteca Pública Prof. Pedro de França Reis, 1992.

MAGNANTI, N. J. Circuito Sul de circulação de alimentos da Rede Ecovida de Agroecologia. Revista Agriculturas, v. 5, n. 2, p. 26-29, jun. 2008. 
MALUF, R. S. Mercados agroalimentares e a agricultura familiar no Brasil: agregação de valor, cadeias integradas e circuitos regionais. Ensaios FEE, v. 25, n. 1, p. 299-322, 2004.

MEDEIROS, T. Feirantes amargam prejuizo desde a mudança da feira há sete meses. Alagoas em tempo, Biblioteca Pública Prof. Pedro de França Reis, 2003.

NARDI, J. B. Acabou-se o fumo: Formação Socioeconômica e espacial em Arapiraca-AL, Ed. Gráfica, Maceió, Alagoas, 2010.

OLIVEIRA, J. L. Da crise do setor fumageiro à diversificação produtiva em Arapiraca/AL: o projeto cinturão verde. Maceió, 2007. 108 f. Dissertação (Mestrado em Desenvolvimento sustentável Regional) - Universidade Federal de Alagoas, 2007.

SATO, Leny. Processos cotidianos de organização do trabalho na feira livre. Psicologia \& Sociedade, v. 19, n. 1, p. 95-102, 2007.

SCARABELOT, M.; SCHNEIDER, S. As cadeias agroalimentares curtas e desenvolvimento localum estudo de caso no município de Nova Veneza/SC. Revista Faz Ciência, v. 14, n. 19, p. 101, 2012.

SILVA, M. N. et al. A agricultura familiar e os circuitos curtos de comercialização de alimentos: estudo de caso da feira livre do município de Jaguarão, RS, Brasil. Espacios, v. 38, n. 47, Pág. 7, 2017.

SOUZA-SEIDL, R.; BILLAUD. JEAN-PAUL. O casamento entre os circuitos curtos e a agricultura de base. In. BRANDENBURG, A. BILLAUD. JEAN-PAUL; LAMINE, C. Redes de Agroecologias: experiências no Brasil e na França Organizadores, Kariós Edições, 2015, p.134-170.

SPOSITO, E. C.; DE ABREU, L. S. Diversidade da produção familiar e da comercialização de produtos orgânicos de Vitória (ES). REDES: Revista do Desenvolvimento Regional, v. 22, n. 3, p. 292-315, 2017. 